\title{
Comparison of satellite, thermochron and air temperatures at Summit, Greenland, during the winter of 2008/09
}

\author{
Lora S. KOENIG, Dorothy K. HALL \\ Cryospheric Sciences Branch, NASA Goddard Space Flight Center, Code 614.1, Greenbelt, Maryland 20771, USA \\ E-mail: lora.s.koenig@nasa.gov
}

\begin{abstract}
Current trends show a rise in Arctic surface and air temperatures, including over the Greenland ice sheet where rising temperatures will contribute to increased sea-level rise through increased melt. We aim to establish the uncertainties in using satellite-derived surface temperature for measuring Arctic surface temperature, as satellite data are increasingly being used to assess temperature trends. To accomplish this, satellite-derived surface temperature, or land-surface temperature (LST), must be validated and limitations of the satellite data must be assessed quantitatively. During the 2008/ 09 boreal winter at Summit, Greenland, we employed data from standard US National Oceanic and Atmospheric Administration (NOAA) air-temperature instruments, button-sized temperature sensors called thermochrons and the Moderate Resolution Imaging Spectroradiometer (MODIS) satellite instrument to (1) assess the accuracy and utility of thermochrons in an ice-sheet environment and (2) compare MODIS-derived LSTs with thermochron-derived surface and air temperatures. The thermochron-derived air temperatures were very accurate, within $0.1 \pm 0.3^{\circ} \mathrm{C}$ of the NOAA-derived air temperature, but thermochron-derived surface temperatures were $\sim 3^{\circ} \mathrm{C}$ higher than MODIS-derived LSTs. Though surface temperature is largely determined by air temperature, these variables can differ significantly. Furthermore, we show that the winter-time mean air temperature, adjusted to surface temperature, was $\sim 11^{\circ} \mathrm{C}$ higher than the winter-time mean MODIS-derived LST. This marked difference occurs largely because satellite-derived LSTs cannot be measured through cloud cover, so caution must be exercised in using time series of satellite LST data to study seasonal temperature trends.
\end{abstract}

\section{INTRODUCTION}

Since 1950, average annual near-surface air temperatures in the Arctic have risen by $2-3^{\circ} \mathrm{C}$, with winter-time temperatures rising by up to $4^{\circ} \mathrm{C}(\mathrm{ACIA}, 2005)$. A corresponding rise is also evident in Arctic land-surface temperature (LST) derived from infrared satellite instruments (Comiso, 2003). This warming is particularly important to monitor over the Greenland ice sheet because of its potentially large contribution to sea-level rise, which predictions place at $0.16-$ $0.53 \mathrm{~m}$ by 2100 (Pfeffer and others, 2008). The Greenland ice sheet has experienced enhanced melting and negative mass balance in recent years (e.g. Luthcke and others, 2006).

Here we investigate the capability of thermochrons to measure surface temperatures at Summit, Greenland, to validate satellite-derived surface temperatures. A thermochron is a small $(\sim 1.5 \mathrm{~cm})$, inexpensive, programmable temperature sensor and data logger. First, we quantify the accuracy of the thermochron in the extreme ice-sheet wintertime environment compared with US National Oceanic and Atmospheric Administration (NOAA) 2 m air temperatures. We then compare thermochron temperatures with Moderate Resolution Imaging Spectroradiometer (MODIS)-derived surface temperatures from the LST standard product to determine the absolute accuracy of the satellite-derived LSTs. We also assess spatial variability in surface temperature within a $\sim 1 \mathrm{~km} \times 1 \mathrm{~km}$ area near Summit.

\section{BACKGROUND}

Extreme temperatures, winds and the isolated environment make in situ temperature records across Greenland temporally and spatially sparse (Box, 2002). Since the mid1990s the Greenland Climate Network (GC-Net) has measured near-surface air temperatures and, in some cases, surface temperatures across the Greenland ice sheet at approximately 18 automatic weather station (AWS) locations (Steffen and Box, 2001). While the AWS data are invaluable, more complete spatial and temporal coverage is needed to monitor temperature trends across Greenland. This has prompted the use of thermochrons to measure surface and air temperatures, and satellite remote sensing to measure LSTs. We use the general term LST for all satellitederived surface temperatures over the ice sheet.

There is a considerable body of literature on the remote sensing of surface temperature of the Greenland ice sheet (e.g. Haefliger and others, 1993; Stroeve and others, 1996; Stroeve and Steffen, 1998; Hall and others, 2006, 2008a,b, 2009; Fausto and others, 2007; Lampkin and Peng, 2008). In addition, there is a more extensive body of literature on the remote sensing of Arctic surface temperatures, including land ice and sea ice (e.g. Key and Haefliger, 1992; Lindsay and Rothrock, 1993; Stone and Key, 1993; Comiso, 1994, 2006; Yu and others, 1995; Key and others, 1997; Comiso and others, 2003; Wang and Key, 2003, 2005a,b; Hall and others, 2004). Researchers use a variety of methods to calculate LST from a single or multiple infrared channels; some of these are reviewed by Hall and others (2008a) and are not reviewed further here.

Satellite sensors with infrared channels (e.g. Advanced Very High Resolution Radiometer (AVHRR), MODIS, Advanced Thermal Emission and Reflection Radiometer (ASTER) and Enhanced Thematic Mapper Plus (ETM+)) are used to measure LSTs by measuring radiance emitted from 


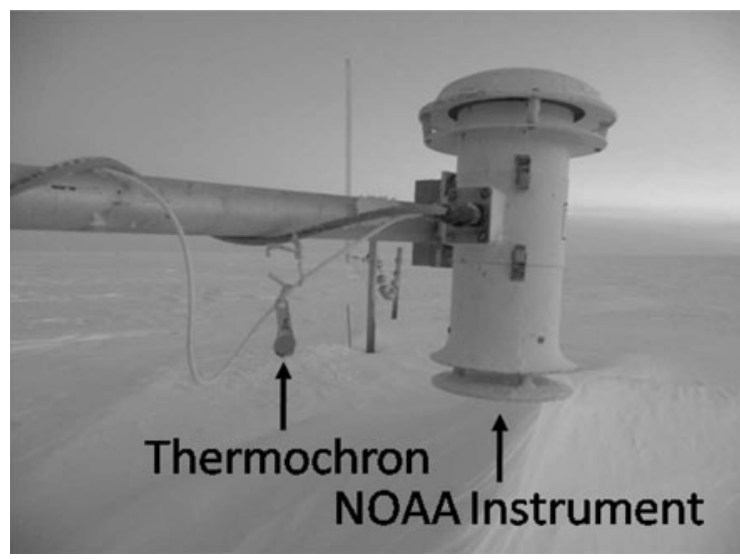

Fig. 1. Picture of thermochron (small $(\sim 1.5 \mathrm{~cm})$ instrument hanging just left of center), measuring the $\sim 2 \mathrm{~m}$ air temperature mounted next to a NOAA temperature station.

the land surface or, in the case studied here, the snow surface. The radiance of the surface is proportional to the emissivity and physical temperature.

Hall and others (2008a) compared LST products from three different infrared satellite sensors over the Greenland ice sheet and found that the satellite-derived LST products were in good agreement, within $\sim 0.5^{\circ} \mathrm{C}$. However, the satellite-derived LSTs did not agree as well with the GC-Net AWS near-surface air temperatures, with a root-mean-square error (RMSE) of $\sim 2^{\circ} \mathrm{C}$. This uncertainty was attributed, at least in part, to the LST variability within a satellite pixel that was not captured or characterized well by the point-location AWS. Over sea ice, MODIS-derived ice-surface temperatures were compared with air temperatures from drifting buoys, and an RMSE of $1.6^{\circ} \mathrm{C}$ was found, with the MODIS ice-surface temperatures lower than the air temperatures after the bias was removed (Hall and others, 2004).

The greatest limitation of satellite remote sensing of LST in the Arctic is the inability to measure LST accurately through cloud cover or fog. When a winter storm occurs over the Greenland ice sheet, near-surface air temperatures rise due to turbulent mixing with the warmer air above. For example, Miller (1956) reported temperature increases of up to $50^{\circ} \mathrm{C}$ on the ice sheet 2-3 days after storms when higher wind speeds caused mixing of warm maritime air with the cold surface layer. Other researchers have also found large increases in temperature during winter storms (e.g. Stroeve and Steffen, 1998; Steffen and Box, 2001). This reduces the accuracy of surface temperature measurements on a monthly or annual timescale using remotely sensed data, because LSTs are not acquired through cloud cover.

Comiso (2000) compared 1992 monthly averages of AVHRR and station near-surface air temperatures on the Antarctic ice sheet and concluded that the clear-sky AVHRR LSTs were colder during winter compared with station temperatures, by $0.5 \pm 1.5^{\circ} \mathrm{C}$. He attributed this difference to the absence of satellite-derived LST measurements during cloudy conditions. Over sea ice during the Surface Heat Budget of the Arctic Ocean (SHEBA) experiment (Perovich and Elder, 2001) in the central Arctic, Comiso (2003) used in situ monthly surface temperature from October 1997 through September 1998 to compare with clear-sky AVHRR-derived LSTs. While overall good agreement $(R=0.997, \mathrm{RMSE}=$ $0.05^{\circ} \mathrm{C}$ ) was found, he also found a difference of $-0.44^{\circ} \mathrm{C}$

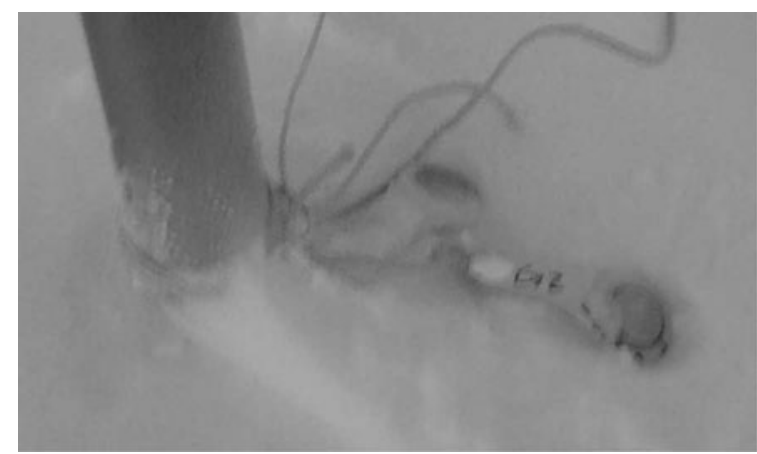

Fig. 2. Picture of the paired thermochrons measuring snow surface temperatures.

during the winter, with the satellite-derived LSTs being lower than the station temperatures (results of the opposite sign were found for the spring and summer data). Using MODIS LST products, Hall and others (2006) produced LST maps showing mean melt-season and mean annual LST and concluded that the mean winter-time LST did not represent the actual temperature, as only a few days of LST data in each of the winter months were available to develop the maps, due to cloud masking, so the mean annual LST was biased (for discussions of surface temperatures beneath cloud cover on the Greenland ice sheet see Miller, 1956; Stroeve and Steffen, 1998; Steffen and Box, 2001).

\section{METHODS}

Thermochron sensors are small, self-sufficient digital thermometers and data loggers that operate over a temperature range from $-40^{\circ} \mathrm{C}$ to $+85^{\circ} \mathrm{C}$ and can store approximately 11 months of hourly temperature data (Fig. 1). Thermochrons are part of the iButton ${ }^{\circledR}$ line of sensors developed by Maxim/Dallas Semiconductor (http://www.maxim-ic.com). DS 1922L Thermochrons, used in this study, have a reported accuracy of $-0.8^{\circ} \mathrm{C}$ to $+1.5^{\circ} \mathrm{C}$ for a temperature range from $-40^{\circ} \mathrm{C}$ to $-10^{\circ} \mathrm{C}$, and $\pm 0.5^{\circ} \mathrm{C}$ for a temperature range from $-10^{\circ} \mathrm{C}$ to $+65^{\circ} \mathrm{C}$, though higher accuracies than $\pm 0.5^{\circ} \mathrm{C}$ have been found in other studies (Hubbart and others, 2005; Lundquist and Lott, 2008). These sensors answer the need to deploy a rugged, low-cost, autonomous and reliable temperaturesensing instrument in the harsh ice-sheet environment.

From 17 November 2008 to 12 February 2009, six thermochrons were deployed at Summit to measure $2 \mathrm{~m}$ air temperatures and snow surface temperatures (Figs 1 and 2). Air temperature was measured by a single thermochron located $\sim 2 \mathrm{~m}$ above two paired thermochrons, placed $\sim 10 \mathrm{~cm}$ apart on the snow surface, measuring the surface temperature. (The air temperature is reported at $\sim 2 \mathrm{~m}$ because drifts formed throughout the camp during the winter, reducing the distance between the air-temperature sensor and the snow surface by $\sim 0.5 \mathrm{~m}$.) This configuration of three thermochrons was deployed at two locations at Summit, sites 1 and 2, approximately $800 \mathrm{~m}$ apart.

The thermochrons were checked daily to ensure that they were free of rime ice, and that those located on the snow surface were sited precisely at the snow-air interface. The snow surface thermochrons were rarely buried by snow $(<5$ days throughout the season) and were never buried by $>1 \mathrm{~cm}$ of snow. Since it cannot be determined when they were 


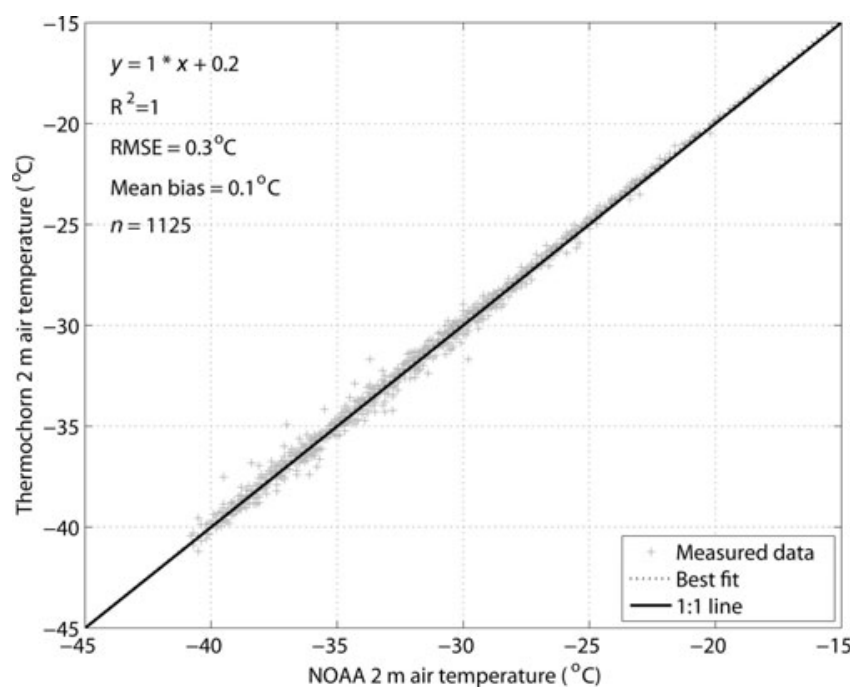

Fig. 3. Comparison of $\sim 2 \mathrm{~m}$ air temperatures from NOAA temperature instrument and thermochron at site 1 .

buried, these temperatures are left in the dataset. These few insulated data points should not affect results because the snow cover was thin and, given a typical thermal conductivity for snow, it would take $<1$ hour for the air temperature to diffuse into the snow cover.

At site 1, a thermochron was placed beside a NOAA temperature instrument at a height of $\sim 2 \mathrm{~m}$ (Fig. 1) to determine the absolute accuracy of the thermochrons. The NOAA instrument is a Logan Enterprises model 4150 probe inside a Cambridge aspirator housing with a military specification fan and radiation shield. We consider the NOAA temperature to be the 'true' temperature. The sensors recorded temperatures at the same time. The difference between the internal clock and the computer clock at the end of the season was $<1 \mathrm{~min}$.

The MODIS LST product used for this study is the swathbased Version 5.0 product (MOD11_L2) from the Terra satellite (Wan and others, 2002; Wan, 2008). This product uses MODIS bands $31(10.78-11.28 \mu \mathrm{m})$ and $32(11.77-$ $12.27 \mu \mathrm{m})$ to calculate LST using a split-window technique (Wan and Dozier, 1996). This technique achieves some correction for atmospheric water-vapor effects by using the difference in water-vapor absorption between channels 31 $(11 \mu \mathrm{m})$ and $32(12 \mu \mathrm{m})$, but because the polar atmosphere during winter has very low humidity, little or no correction is required for atmospheric effects caused by water vapor. A constant, year-round emissivity of 0.993 and 0.990 is prescribed for bands 31 and 32, respectively. In situ surfacetemperature measurements from the thermochrons were acquired within $30 \mathrm{~min}$ of the MODIS LST measurements.

The thermochron data allow for new comparisons of temperature datasets. When two temperature datasets were compared, the following statistics were calculated: the number of elements, $n$; the linear least-squares fit equation; and the Pearson correlation coefficient, $R^{2}$. Also reported here are the mean bias, or mean difference, and the RMSE. The mean bias is calculated as

$$
\text { Mean bias }=\frac{1}{n} \sum y-x .
$$

The RMSE is the absolute value of the average difference between the measured dependent temperature, $y$, and the

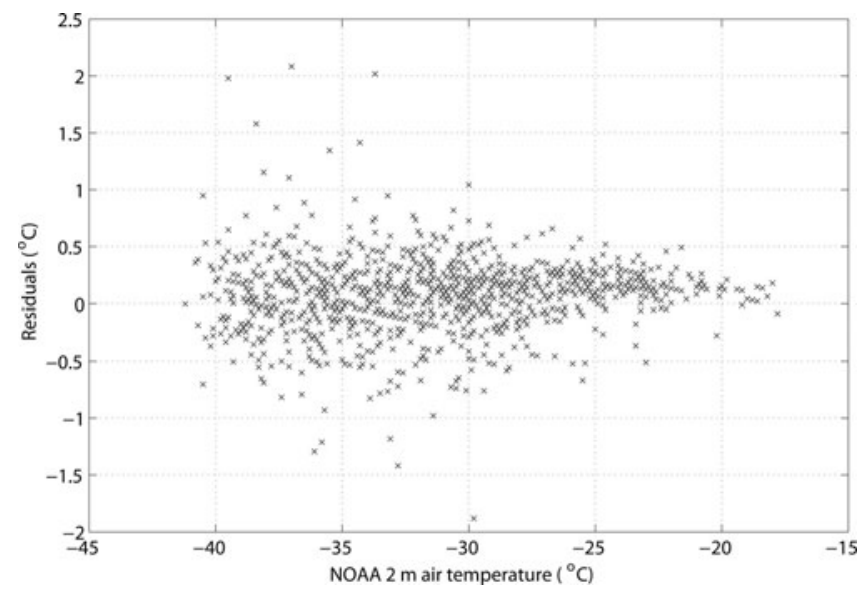

Fig. 4. Residuals of $\mathrm{NOAA} \sim 2 \mathrm{~m}$ air temperature and the thermochron $\sim 2 \mathrm{~m}$ air temperature, showing that the accuracy of the thermochron temperature measurement decreases near the minimum recordable temperature $\left(\sim-41^{\circ} \mathrm{C}\right)$.

predicted temperatures, $y^{\prime}$, determined by the linear leastsquares fit of the data:

$$
\text { RMSE }=\sqrt{\frac{1}{n} \sum(x-y)^{2}} .
$$

Additionally, $t$ tests were performed to test the hypothesis that the means of two temperature datasets are statistically different at a 0.05 significance level. This statistical test cannot prove that temperatures measured between sensors are equal; it can only show that they are or are not statistically different.

\section{RESULTS}

The thermochrons monitored both air and surface temperature well in the harsh polar conditions. They acquired temperature measurements reliably every hour, but they cannot record temperatures lower than $-41^{\circ} \mathrm{C}$. (The thermochron specifications state a minimum operating temperature of $-40^{\circ} \mathrm{C}$, but we found that they recorded to a slightly lower temperature.) Only $\sim 40 \%$ of the data were available for comparison with the satellite LST data, as temperatures for the rest of the time were at or below $-41^{\circ} \mathrm{C}$.

\subsection{Accuracy of thermochrons}

Before using thermochrons to validate the accuracy of the LSTs, we first established the absolute accuracy of the thermochrons using two comparisons. First, we compared coincident hourly air temperatures from the thermochron and the NOAA instrument at site 1. Thermochron air temperatures were within $0.1{ }^{\circ} \mathrm{C}$ (mean bias or mean difference) of the NOAA temperatures, with a RMSE of $0.3^{\circ} \mathrm{C}$ (Fig. 3), giving an accuracy of $\pm 0.3^{\circ} \mathrm{C}$ as determined by the RMSE. The $t$ tests could not distinguish statistically between the temperature datasets, and there was nearly perfect correlation between them. Figure 4 shows a plot of the residuals between the air temperatures, with a decrease in accuracy as the thermochron approaches its minimum temperature.

Second, we compared coincident hourly measurements from the two proximal thermochrons measuring surface temperature at both sites. The mean differences between the 


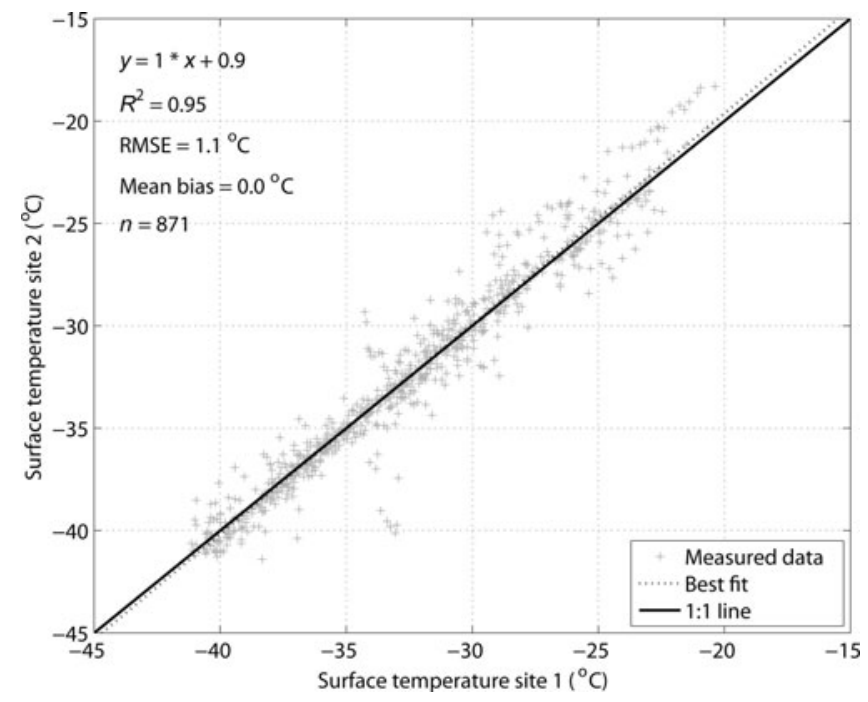

Fig. 5. Spatial comparison of surface temperatures at sites 1 and 2 showing no mean bias. These sited are located $\sim 800 \mathrm{~m}$ apart.

proximal thermochrons were $0.1^{\circ} \mathrm{C}$ at site 1 and $0.2^{\circ} \mathrm{C}$ at site 2 . The RMSEs between the proximal thermochrons were $0.4^{\circ} \mathrm{C}$ at site 1 and $0.5^{\circ} \mathrm{C}$ at site 2 , so the accuracy, defined by the larger RMSE value, is $\pm 0.5^{\circ} \mathrm{C}$. The proximal thermochrons have double the error associated with one thermochron when compared to the NOAA temperature, showing a multiplicative decrease in accuracy when comparing two thermochron temperatures.

\subsection{Area-wide comparison of surface temperatures}

Spatial variation within $\mathrm{a} \sim 1 \mathrm{~km} \times 1 \mathrm{~km}$ area (the size of a MODIS LST pixel at nadir) including Summit was characterized by measuring coincident hourly surface temperatures at sites 1 and 2. Again, because there were two proximal surface temperature measurements at the two sites, four comparisons were possible. The results were nearly identical, so the results of only one comparison are shown (Fig. 5). The $t$ tests could not distinguish statistically between any of the surface temperature datasets, and the mean difference ranged from $-0.2^{\circ} \mathrm{C}$ to $0.1^{\circ} \mathrm{C}$, with an RMSE of $1.1^{\circ} \mathrm{C}$. The means and standard deviations of all four surface temperature datasets were identical within the thermochron accuracy reported here $\left( \pm 0.3^{\circ} \mathrm{C}\right)$.

Based on comparisons of surface temperatures recorded at two locations, we can assume that the surface temperatures are homogeneous across a MODIS LST pixel at nadir, at least during our study period. This result, combined with results from a summer 2006 study showing no significant density differences in five snow pits taken within a $25 \mathrm{~km}$ radius of Summit (Koenig, 2008), shows Summit is a good site for satellite calibration studies. Thus, point measurements taken at Summit represent a valid characterization of a $1 \mathrm{~km} \times 1 \mathrm{~km}$ satellite pixel.

\subsection{Comparison of MODIS-derived LSTs with thermochron surface temperatures}

Hourly surface temperature at site 1 was compared with MODIS LSTs during the study period (Fig. 6). The MODIS LST underestimated the coincident hourly surface temperature by $3.4^{\circ} \mathrm{C}$. There is, however, a large gap in the temperature data available for comparison because the

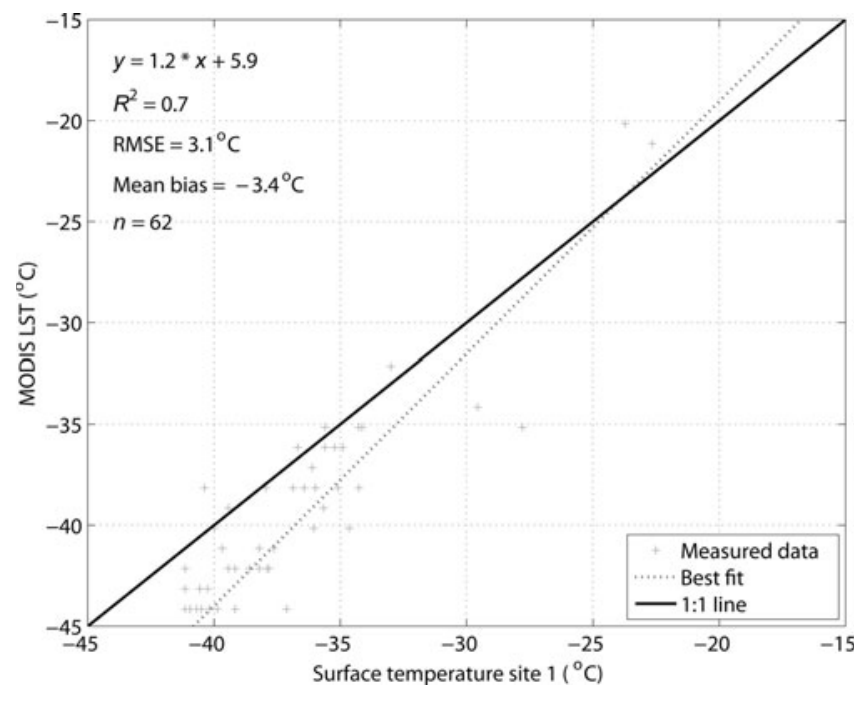

Fig. 6. Comparison of surface temperature with MODIS LST for the area over Summit. The large data gap between $\sim-32^{\circ} \mathrm{C}$ and $-22^{\circ} \mathrm{C}$ occurs because clouds (determined by the MODIS cloud mask) precluded LST measurements during winter storms when surface and air temperatures increased.

MODIS cloud mask acted as a temperature mask eliminating all but four data points above $-32^{\circ} \mathrm{C}$. The warmer surface temperatures resulting from winter storms that brought clouds were masked by the MODIS cloud mask.

In total, $62 \%$ of the MODIS LSTs during this study were masked for cloud cover, and only $8 \%$ of the LSTs had corresponding surface temperature data that were above $-41^{\circ} \mathrm{C}$. To assess how well the MODIS cloud mask (an integral part of the LST product) operated during our study period, we compared ground observations of cloud cover to satellite observations taken within $72 \mathrm{~min}$. Results show that the cloud mask correctly identifies all clear-sky days and, though it had a $12 \%$ error rate due to calculating an LST when there was, in fact, cloud cover, the error introduced was smaller than the total mean bias. The MODIS cloud mask performed well, correctly masking cloud-covered days.

Because most AWS instruments nominally measure a $2 \mathrm{~m}$ air temperature, not a surface temperature, and because more $2 \mathrm{~m}$ air temperatures than surface temperatures exist over ice sheets, it is necessary to quantify the difference between the two temperatures. Coincident hourly data from the $\sim 2 \mathrm{~m}$ air temperatures measured by the thermochron and the NOAA instrument were compared at site 1 to the two proximal surface temperature measurements, for a total of four comparisons. The mean bias between the air temperatures and the surface temperatures ranged from $-1.3^{\circ} \mathrm{C}$ to $-1.5^{\circ} \mathrm{C}$ at site 1 and from $-1.5^{\circ} \mathrm{C}$ to $-1.7^{\circ} \mathrm{C}$ at site 2. Thus the average difference between the coincident hourly $\sim 2 \mathrm{~m}$ air temperature and the surface temperature during the study period is $-1.5 \pm 0.2^{\circ} \mathrm{C}$, with higher air temperatures than surface temperatures.

Figure 7 shows the comparison between the MODIS LST and the $\sim 2 \mathrm{~m} \mathrm{NOAA}$ air temperatures. Over a temperature range from $-60^{\circ} \mathrm{C}$ to $-15^{\circ} \mathrm{C}$, the MODIS LSTs are lower than the air temperatures by an average of $5.5^{\circ} \mathrm{C}$. Taking into account the adjustment of $-1.5 \pm 0.2^{\circ} \mathrm{C}$ from air temperature to surface temperature, the $\sim 3^{\circ} \mathrm{C}$ cold bias in the MODIS LSTs holds for the larger range of temperatures. 


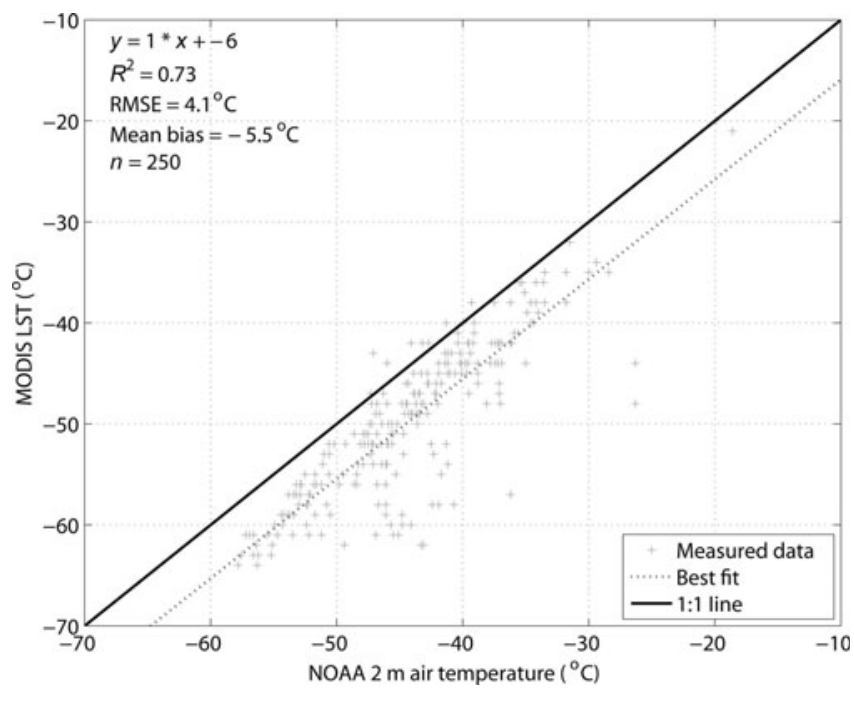

Fig. 7. Comparison of the $\sim 2 \mathrm{~m} \mathrm{NOAA}$ air temperature with MODIS LST for the area over Summit.

When temperatures ranged from $\sim-32^{\circ} \mathrm{C}$ to $-22^{\circ} \mathrm{C}$, the MODIS LSTs could not be compared with the surface temperature because the cloud mask precluded obtaining LST measurements during winter storms (when cloud cover prevails). The mean winter-time air temperature from the NOAA instrument was $-37.5^{\circ} \mathrm{C}$, while the mean MODIS LST over the same period was $-50^{\circ} \mathrm{C}$. Taking into account the adjustment of $-1.5 \pm 0.2^{\circ} \mathrm{C}$ from air temperature to surface temperature, the MODIS LST is $\sim 11.0^{\circ} \mathrm{C}$ lower than the NOAA-derived surface temperatures. This difference in mean winter temperature is largely due to cloud masking, as discussed previously. We expect this difference between mean winter in situ temperature and MODIS LST to hold over other areas of the ice sheets and with different infrared satellite temperature measurements.

To further investigate bias introduced by averaging satellite-derived LSTs, we compared air and surface temperatures. NOAA air temperatures and thermochron surface temperatures were compared with MODIS LSTs only during satellite overpass times. There were 654 satellite observations during the study period, of which $250(38 \%)$ were clear-sky observations. The mean air temperature (from the NOAA instrument) for cloud-masked observation times was $-32.3^{\circ} \mathrm{C}$, whereas the mean air temperature for clear-sky observations was $-44.3^{\circ} \mathrm{C}$. This result shows a bias of $12^{\circ} \mathrm{C}$ for the $\sim 2 \mathrm{~m}$ air temperature between cloudy and clear days. The same comparison was made for site 1 for thermochron surface temperature measurements where the cloud-masked mean was $-32.1^{\circ} \mathrm{C}$, compared with the mean for clear-sky observations of $-37.3^{\circ} \mathrm{C}$. This again shows higher air temperatures for cloud-masked days but cannot truly capture the magnitude of the difference since the thermochron data exclude temperatures below $-41^{\circ} \mathrm{C}$.

\section{THERMOCHRON LIMITATIONS}

There are two major limitations to using thermochrons in an ice-sheet environment. First, the stated minimum of $-40^{\circ} \mathrm{C}$ restricts their use in the cryosphere, especially during winter. Second, thermochrons must be in physical contact with a reading device for a user to retrieve data. This requires access to the thermochrons at the end of the study period and does not allow for real-time transmission.

\section{DISCUSSION}

We have determined the accuracy of thermochrons for measuring surface and air temperatures during winter in a controlled environment in which the instruments were serviced daily. To broaden the use of thermochrons in an ice-sheet environment, we will need to study thermochron surface temperatures year-round where the instruments are not serviced. It is expected that unattended thermochrons will become encased in rime ice that could affect the airand surface-temperature reading. Studies are needed to quantify the effects of rime ice on temperatures recorded by unattended thermochrons. Additionally, for thermochron deployments during daylight, radiation shields will need to be developed and tested.

After establishing the accuracy of the thermochrons and the homogeneity of surface temperature at Summit for a $\sim 1 \mathrm{~km} \times 1 \mathrm{~km}$ MODIS LST pixel at nadir, we used them to validate MODIS LSTs. The homogeneity in surface and air temperature that we established near Summit is not characteristic of the entire ice sheet, so most areas on the ice sheet will require more surface measurements for valid characterization.

There was a $1.0^{\circ} \mathrm{C}$ warm bias between the surface temperature and the $2 \mathrm{~m}$ air temperature at Summit from 2000 to 2001 (as determined by K. Steffen and reported by Hall and others, 2008a). In our study, the opposite result was found: surface temperatures were $\sim 1.5^{\circ} \mathrm{C}$ cooler than the $\sim 2 \mathrm{~m}$ air temperatures. This difference may be explained by the timing of the data collection: the Summit data reported by Hall and others (2008a) represented an entire year, whereas our data were acquired during the winter only, from 17 November 2008 to 12 February 2009. Because snow has a lower thermal diffusivity than air, it remains colder than air during this period, as lower winter temperatures transition to higher spring temperatures. (Though this is typical over an ice or snow surface during winter, the $2 \mathrm{~m}$ air temperature can be lower than the surface temperature depending on meteorological conditions.) Similar results were found at the SHEBA site in the central Arctic. Comiso (2003) found that the $2 \mathrm{~m}$ air temperature was $0.95^{\circ} \mathrm{C}$ higher than the surface temperature during winter. Also over Arctic sea ice during winter, Radionov and others (1997) found a $2 \mathrm{~m}$ air temperature up to $7^{\circ} \mathrm{C}$ higher than the surface temperature under cloud-free conditions, but no temperature difference between the surface and $2 \mathrm{~m}$ when there was a continuous cloud cover. In the winter, snow and ice surface temperatures tend to be lower than air temperatures. Comiso (2003) explained this by winter-time inversions seen during the SHEBA experiment. Further study of air-temperature profiles is needed at Summit, but this mechanism along with higher temperatures during winter storms can explain the differences we found between surface and air temperatures.

\section{CONCLUSIONS}

This work shows that thermochrons provide a highly accurate method of determining surface temperature during the winter at Summit. Thermochron-derived surface temperatures are accurate to within $0.1 \pm 0.3^{\circ} \mathrm{C}$ of the NOAA 
temperature instrument for temperatures in the range $-40^{\circ} \mathrm{C}$ to $-15^{\circ} \mathrm{C}$. We also show surface-temperature homogeneity in a $\sim 1 \mathrm{~km} \times 1 \mathrm{~km}$ area including Summit. Once we established the accuracy of the thermochrons over an area approximately the size of a MODIS LST pixel at nadir, we compared thermochron-derived surface temperatures with LSTs from the standard MODIS LST product (MOD11_L2). Under clear-sky conditions the MODIS LSTs have an accuracy of $\sim 3^{\circ} \mathrm{C}$, with the MODIS LSTs being lower than the thermochron-derived surface temperatures. Our results also show that mean-seasonal LSTs have a marked cold bias compared with mean-seasonal temperatures adjusted to surface temperatures, with the mean-seasonal LST being $\sim 11^{\circ} \mathrm{C}$ lower during the study period. This is attributed to the fact that LSTs are only obtained during clear-sky conditions, whereas cloud cover is often associated with winter storms that bring higher air and surface temperatures.

Though it has some important limitations, the use of thermochrons has a great and as yet largely untapped potential for characterizing ice-sheet surface and air temperatures. In addition, thermochrons can be used to augment weather-station data, and to validate satellitederived LSTs.

\section{ACKNOWLEDGEMENTS}

We thank T. Mefford at NOAA's Earth System Research Laboratory for allowing the use of the NOAA temperatures, $\mathrm{CH} 2 \mathrm{M}$ HILL Polar Services for logistics support, and K. Huybers for helping monitor the thermochrons. Part of the work was supported by NASA's Cryospheric Sciences Program.

\section{REFERENCES}

Arctic Climate Impact Assessment (ACIA). 2005. An introduction to the Arctic Climate Impact Assessment. In Arctic Climate Impact Assessment: scientific report. Cambridge, etc., Cambridge University Press, 1-29.

Box, J.E. 2002. Survey of Greenland instrumental temperature records: 1873-2001. Int. J. Climatol., 22(15), 1829-1847.

Comiso, J.C. 1994. Surface temperatures in the polar regions from Nimbus 7 temperature humidity infrared radiometer. J. Geophys. Res., 99(C3), 5181-5200.

Comiso, J.C. 2000. Variability and trends in Antarctic surface temperatures from in situ and satellite infrared measurements. J. Climate, 13(10), 1674-1696.

Comiso, J.C. 2003. Warming trends in the Arctic from clear satellite observations. J. Climate, 16(21), 3498-3510.

Comiso, J.C. 2006. Abrupt decline in the Arctic winter sea ice cover. Geophys. Res. Lett., 33(18), L18504. (10.1029/ 2006GL027341.)

Comiso, J.C., J. Yang, S. Honjo and R.A. Krishfield. 2003. Detection of change in the Arctic using satellite and in situ data. J. Geophys. Res., 108(C12), 3384. (10.1029/2002JC001347.)

Fausto, R.S., C. Mayer and A. Ahlstrøm. 2007. Satellite-derived surface type and melt area of the Greenland ice sheet using MODIS data from 2000 to 2005. Ann. Glaciol., 46, 35-42.

Haefliger, M., K. Steffen and C. Fowler. 1993. AVHRR surface temperature and narrow-band albedo comparison with ground measurements for the Greenland ice sheet. Ann. Glaciol., 17, 49-54.

Hall, D.K., J. Key, K.A. Casey, G.A. Riggs and D.J. Cavalieri. 2004. Sea ice surface temperature product from MODIS. IEEE Trans. Geosci. Remote Sens., 42(5), 1076-1087.
Hall, D.K., R.S. Williams, Jr and K.A. Casey. 2006. Satellite-derived, melt-season surface temperature of the Greenland Ice Sheet (2000-2005) and its relationship to mass balance. Geophys. Res. Lett., 33(11), L11501. (10.1029/2006GL026444.)

Hall, D.K., J.E. Box, K.A. Casey, S.J. Hook, C.A. Shuman and K. Steffen. 2008a. Comparison of satellite-derived and in-situ observations of ice and snow surface temperatures over Greenland. Remote Sens. Environ., 112(10), 3739-3749.

Hall, D.K., R.S. Williams, Jr, S.B. Luthcke and N.E. Digirolamo. 2008b. Greenland ice sheet surface temperature, melt and mass loss: 2000-2006. J. Glaciol., 54(184), 81-93.

Hall, D.K., S.V. Nghiem, C.B. Schaaf, N.E. DiGirolamo and G. Neumann. 2009. Evaluation of surface and near-surface melt characteristics on the Greenland ice sheet using MODIS and QuikSCAT data. J. Geophys. Res., 114(F4), F04006. (10.1029/ 2009JF001287.)

Hubbart, J., T. Link, C. Campbell and D. Cobos. 2005. Evaluation of a low-cost temperature measurement system for environmental applications. Hydrol. Process., 19(7), 1517-1523.

Key, J. and M. Haefliger. 1992. Arctic ice surface temperature retrieval from AVHRR thermal channels. J. Geophys. Res., 97(D5), 5885-5893.

Key, J.R., J.B. Collins, C. Fowler and R.S. Stone. 1997. High-latitude surface temperature estimates from thermal satellite data. Remote Sens. Environ., 61(2), 302-309.

Koenig, L.S. 2008. Firn properties relevant to passive microwave remote sensing. (PhD thesis, University of Washington.)

Lampkin, D. and R. Peng. 2008. Empirical retrieval of surface melt magnitude from coupled MODIS optical and thermal measurements over the Greenland Ice Sheet during the 2001 ablation season. Sensors, 8(8), 4915-4947.

Lindsay, R. and D. Rothrock. 1993. The calculation of surface temperature and albedo of Arctic sea ice from AVHRR. Ann. Glaciol., 17, 391-397.

Lundquist, J.D. and F. Lott. 2008. Using inexpensive temperature sensors to monitor the duration and heterogeneity of snowcovered areas. Water Resour. Res., 44, W00D16. (10.1029/ 2008WR007035.)

Luthcke, S.B. and 8 others. 2006. Recent Greenland ice mass loss by drainage system from satellite gravity observations. Science, 314(5803), 1286-1289.

Miller, D.H. 1956. The influence of snow cover on local climate in Greenland. J. Meteorol., 13(1), 112-120.

Perovich, D.K. and B.C. Elder. 2001. Temporal evolution of Arctic sea-ice temperature. Ann. Glaciol., 33, 207-211.

Pfeffer, W.T., J.T. Harper and S. O'Neel. 2008. Kinematic constraints on glacier contributions to 21 st-century sea-level rise. Science, 321(5894), 1340-1343.

Radionov, V.F., N.N. Bryazgin and E.I. Alexandrov. 1997. The snow cover of the Arctic Basin. Seattle, WA, University of Washington. Applied Physics Laboratory. (APL Tech. Rep. APL-UW TR 9701.)

Steffen, K. and J. Box. 2001. Surface climatology of the Greenland ice sheet: Greenland Climate Network 1995-1999. J. Geophys. Res., 106(D24), 33,951-33,964.

Stone, R.S. and J.R. Key. 1993. The detectability of Arctic leads using thermal imagery under varying atmospheric conditions. J. Geophys. Res., 98(C7), 12,469-12,482.

Stroeve, J. and K. Steffen. 1998. Variability of AVHRR-derived clearsky surface temperature over the Greenland ice sheet. J. Appl. Meteorol., 37(1), 23-31.

Stroeve, J., M. Haefliger and K. Steffen. 1996. Surface temperature from ERS-1 ATSR infrared thermal satellite data in polar regions. J. Appl. Meteorol., 35(8), 1231-1239.

Wan, Z. 2008. A generalized split-window algorithm for retrieving land-surface temperature from space. IEEE Trans. Geosci. Remote Sens., 34(4), 892-905.

Wan, Z. and J. Dozier. 1996. New refinements and validation of the MODIS land-surface temperature/emissivity products. Remote Sens. Environ., 112(1), 59-74. 
Wan, Z., Y. Zhang, Q. Zhang and Z.L. Li. 2002. Validation of the land-surface temperature products retrieved from Terra Moderate Resolution Imaging Spectroradiometer data. Remote Sens. Environ., 83(1-2), 163-180.

Wang, X. and J.R. Key. 2003. Recent trends in Arctic surface, cloud, and radiation properties from space. Science, 299(5613), $1725-1728$

Wang, X. and J.R. Key. 2005a. Arctic surface, cloud, and radiation properties based on the AVHRR Polar Pathfinder Dataset. Part I: spatial and temporal characteristics. J. Climate, 18(14), $2558-2574$

Wang, X. and J.R. Key. 2005b. Arctic surface, cloud, and radiation properties based on the AVHRR Polar Pathfinder Dataset. Part II: recent trends. J. Climate, 18(14), 2575-2593.

Yu, Y., D.A. Rothrock and R.W. Lindsay. 1995. Accuracy of sea ice temperature derived from the advanced very high resolution radiometer. J. Geophys. Res., $\mathbf{1 0 0}(\mathrm{C} 3)$, 4525-4532.

MS received 1 August 2009 and accepted in revised form 5 June 2010 